\title{
Comparison of planned menus and centre characteristics with foods and beverages served in New York City child-care centres
}

\author{
Andrew Breck ${ }^{1,2, *}$, L Beth Dixon ${ }^{3}$ and Laura Kettel Khan ${ }^{4}$ \\ 'Department of Population Health, New York University School of Medicine, 227 East 30th Street - 6th floor, \\ New York, NY 10016, USA: ${ }^{2}$ Department of Public Administration, New York University Wagner School of Public \\ Service, 295 Lafayette Avenue - 2nd floor, New York, NY 10012, USA: ${ }^{3}$ Department of Public Health, Food Studies \\ and Nutrition, Syracuse University, Syracuse, NY, USA: ${ }^{4}$ Division of Nutrition, Physical Activity, and Obesity, \\ Centers for Disease Control and Prevention, Atlanta, GA, USA
}

Submitted 3 August 2015: Final revision received 22 December 2015: Accepted 17 February 2016: First published online 10 June 2016

\begin{abstract}
Objective: The present study evaluated the extent to which child-care centre menus prepared in advance correspond with food and beverage items served to children. The authors identified centre and staff characteristics that were associated with matches between menus and what was served.

Design: Menus were collected from ninety-five centres in New York City (NYC). Direct observation of foods and beverages served to children were conducted during 524 meal and snack times at these centres between April and June 2010, as part of a larger study designed to determine compliance of child-care centres with city health department regulations for nutrition.

Setting: Child-care centres were located in low-income neighbourhoods in NYC. Results: Overall, $87 \%$ of the foods and beverages listed on the menus or allowed as substitutions were served. Menu items matched with foods and beverages served for all major food groups by $>60 \%$. Sweets and water had lower match percentages ( 40 and $32 \%$, respectively), but water was served $68 \%$ of the time when it was not listed on the menu. The staff person making the food and purchasing decisions predicted the match between the planned or substituted items on the menus and the foods and beverages served.

Conclusions: In the present study, child-care centre menus included most foods and beverages served to children. Menus planned in advance have potential to be used to inform parents about which child-care centre to send their child or what foods and beverages their enrolled children will be offered throughout the day.
\end{abstract}

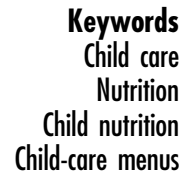

Children attending full-day child care are expected to obtain at least half of their nutrient needs from meals and snacks consumed at the care facility ${ }^{(1)}$. Menus planned in advance for foods and beverages served at child-care centres provide important information for a number of different stakeholders that might have an interest in evaluating a centre based on the quality or content of provided foods and beverages. Having menus that accurately reflect actual items served to children is important for a number of reasons. First, licensing agencies, such as the New York City (NYC) Department of Health and Mental Hygiene (DOHMH), review menus regularly for quality. Inaccurate menus that over-represent the nutritional quality of items provided to children will result in missed opportunities for the DOHMH to provide nutrition education and menu planning services. Second, menus are used to evaluate compliance with the requirements for meal and snack reimbursement at centres that participate in the Child and Adult Care Food Program $(\mathrm{CACFP})^{(2)}$. If menus misrepresent what centres are serving, then it is possible child-care centres are receiving reimbursement for providing nutrition that is not compliant with the programme guidelines. Third, menus show parents and caregivers what foods and beverages are being served. Parents have a choice in selecting the child-care facility to which to send their child. A number of factors may influence this decision. This may include the quality and nutrition that is made available to their child. In order for parents or caregivers to thoroughly assess care options available for their child, it is important that child-care menus present a faithful representation of what is served. Fourth, menus present an opportunity for nutrition education by providing a good example of healthful meals and snacks. In instances in which menus accurately portray unhealthy meals, the menus can signal opportunities for health professionals to intervene and 
provide the centre nutrition education or menu planning assistance.

Many efforts have been made to improve the nutrition practices in early childhood settings, but few studies have evaluated the menus ${ }^{(3,4)}$. The earlier work of Fleischhacker et al. (2006) and Benjamin Neelon et al. (2010) examined the extent to which child-care meal menus reflect items served to children at one urban Head Start centre and eighty-four centres in North Carolina, respectively. The purpose of the present study was to evaluate whether the foods and beverages listed on the menus matched what was served to children at group child-care centres in NYC. We build on the prior literature with an examination of menus and meal observations from a large urban sample that allow us to determine whether centre and staff characteristics were associated with the matched food and beverage items.

\section{Methods}

\section{Study design and sample}

The present study used data from Phase II of the NYC Child Care Evaluation, a multi-method cross-sectional study conducted to determine compliance with the NYC DOHMH regulations for nutrition, physical activity and screen time in 176 licensed group child-care centres ${ }^{(5)}$. Child-care centre visits were conducted between April and June, 2010. Two trained data collectors visited each centre for two consecutive days. During each child-care centre visit data collectors obtained a printed hard copy of the centre's prepared menu. Interviews with centre staff included questions about centre participation in several child-care centre support programmes, including CACFP, Eat Well Play Hard and Head Start, which staff were primarily responsible for creating menus and purchasing food, and where the centre purchased the foods and beverages served to children. Centre staff were aware of the scheduled visits and were asked not to change their behaviours. Centre staff were not informed that the evaluation would include a comparison of the foods and beverages listed on the menus with the foods and beverages served to the children.

Data collectors conducted observations in one classroom of 3- to 4-year-olds at each centre. On average, there were twelve children in a class. The detailed data collection protocol and centre- and child-level descriptive sample statistics are provided in Breck et al. ${ }^{(5)}$. In order to evaluate actual foods and beverages provided to children, data collectors used a Mealtime Observation Form to record types and amounts of all foods and beverages served to the children during all meals and snacks served during the period of attendance. At these full-day childcare centres, the observed meals included breakfast or morning snack (depending on centre start time), lunch and an afternoon snack. Like other institutional meal services, generally all children in each observed classroom received the same meal, snack or beverages. Accordingly, items served during child-care centre meals were observed at the meal level. We considered deviations from the standard meal or snack as accommodations for an individual child's dietary needs and these were not recorded among the items served. These special items were recorded among the child-level consumption data. We have published results from our analysis of child-level consumption behaviour in Dixon et al. ${ }^{(6)}$. The Mealtime Observation Form was adapted from the Environment and Policy Assessment and Observation instrument used in the Nutrition and Physical Activity Self-Assessment for Child Care (NAP SACC) programme ${ }^{(7,8)}$ and from the Meal Observation Form used by the US Department of Agriculture to evaluate meals offered by CACFP family child-care providers ${ }^{(9)}$.

\section{Coding of foods and beverages from menus and items served}

Menus obtained from the child-care centres included information on meals and snacks that were planned to be served during each day of classroom observation. The depth and quality of this information varied significantly. Some menus included portion size for each item (i.e. 6 ounces of apple juice), while other menus simple listed only the type of food or beverage to be served (i.e. apple juice). Three data collectors entered the data recorded on the Mealtime Observation Form and the Nutrition Observation Form into the US National Cancer Institute's Automated Self-Administered 24-Hour Dietary Recall (ASA24) ${ }^{(10)}$. Foods and beverages listed on menus were also entered into the ASA24.

Foods and beverages listed on menus and served to the children were categorized into ten food groups (milk; yoghurt and cheese; water; juice; fruits; vegetables; grains; protein; mixed dishes; sweets) for comparison with the study by Benjamin Neelon et al. ${ }^{(3)}$. Milk was grouped as $\leq 1 \%$ or $>1 \%$ milk fat because the NYC Health Code Article $47^{(11)}$ and the New York State CACFP Healthy Child Meal Pattern ${ }^{(12)}$ require that children 2 years and older drink milk with $1 \%$ or less milk fat. Beverages that were $100 \%$ and $<100 \%$ fruit juice were evaluated separately because the NYC Health Code Article 47 prohibits sugar-sweetened beverages and limits servings of $100 \%$ juice to 6 ounces $/ \mathrm{d}(177 \mathrm{ml} / \mathrm{d})$. The New York State CACFP Healthy Child Meal Pattern does not specify that $100 \%$ juice be served or a maximum amount, but it does require that no more than one serving of juice be served per day ${ }^{(11,12)}$. When possible, foods and beverages with multiple components were coded separately. For example, a cheeseburger was coded as whole wheat bun, romaine lettuce, tomato slice, American cheese and beef patty. Food items without sufficient detail about the individual components were coded as mixed dishes 
(e.g. chicken with rice and mixed vegetables, pot pie, meat lasagne).

Foods and beverages served were coded as: (i) matching a menu item ('match'); (ii) an acceptable substitute of a food item that was listed on the menu ('substitution'); (iii) listed on the menu, but not served with a meal or snack, and not substituted ('omission'); or (iv) being served but not listed on the menu ('addition'). We determined substitutions to be acceptable if the substituted food was in the same food category as the item listed on the menu, e.g. an apple was considered an acceptable substitution for a pear. A 'total match' variable was created by adding the number of foods and beverages served that matched a menu item with the number of acceptable substitutions for that menu item. Food items often not listed on menus, such as condiments (e.g. ketchup, maple syrup), were not coded. Foods and beverages served for special occasions that were not listed on the menus and foods and beverages brought from home for consumption by a single child were also excluded. Portion sizes of foods and beverages were not analysed because most menus did not include information about portion sizes.

\section{Data analysis}

Percentages were determined for the five variables described above:

1. 'Match \%' = (number of foods and beverages served that matched the foods and beverages on the menus/ number of times those foods and beverages were served) $\times 100$;

2. 'Substitution \%' = (number of acceptable substitutions served for foods and beverages on the menus/number of times those foods and beverages were served) $\times 100$

3. 'Omission $\%$ ' = (number of foods and beverages listed on the menus that were not served/number of times those foods and beverages were listed on the menus) $\times 100$;

4. 'Addition $\%$ ' = (number of foods and beverages served but not listed on the menus/number of times those foods and beverages were served) $\times 100$; and

5. 'Total Match \%' = [(number of matched food and beverage Items + number of acceptable substitutions)/ total number of all foods and beverages served] $\times 100$.

Frequencies and percentages of these variables were determined for the ten food groups (i.e. milk; cheese and yoghurt; water; juice; fruits; vegetables; grains; protein; mixed dishes; sweets) and the top five most commonly consumed fruits, vegetables, grains, proteins and mixed dishes from all 2001 food and beverage items served during the two days of observation (Table 1). Frequencies of match variables were also determined by meal occasion (breakfast, morning snack, lunch or afternoon snack; Table 2).
Multivariable regression analyses were run to evaluate potential associations between staff and centre characteristics, including food procurement and production variables, with the number of matches (Table 3). Menus from child-care centres varied by time frame: some menus were daily; other menus were weekly or monthly. Also, some centres used templates produced by the NYC DOHMH or by the CACFP. Some of these templates included food group and serving size suggestions for different age groups for each meal. Our regression models include controls for variation in menu frequency and where food is purchased, and indicators for primary staff responsible for food purchasing and menu production, and the use of templates. Because the outcome measure (total matches) was a proportion with values between 0 and 1 , a generalized linear model with binomial family and logit link was used to estimate these associations. Regression coefficients were estimated with standard errors clustered by child-care centre. Regression analyses were run using the Stata statistical software package version $12 . P<0.05$ was considered statistically significant.

\section{Results}

The study sample included menus with complete data from eighty-eight centres and menus with partial data from seven centres. We completed two days of observation at ninety-three centres and one day of observation at two centres. We conducted direct observation of 524 meals and snacks - an average of $2 \cdot 8$ meals per centre per day of observation. Overall, $87 \%$ of foods and beverages served were listed on the planned menus or considered acceptable substitutions (Table 1). About $14 \%$ of the foods and beverages served were acceptable substitutions and 13\% were additional foods and beverages served but not listed on the menus. About $12 \%$ of foods and beverages listed on the menus were not served.

Milk, cheese and yoghurt, proteins, and mixed dishes had match percentages greater than $80 \%$. Vegetables and grains had match percentages between 72 and $74 \%$. About $33 \%$ of the time fruits listed on the menu had acceptable substitutions and about $16 \%$ of the time vegetables listed on the menu had acceptable substitutions. Cheese and yoghurt items were not served $23 \%$ of the time they were listed on the menus. Water was not served $71 \%$ of the time it was listed on the menus. However, about $68 \%$ of the time water was served it was not listed on the menus. In addition, $25 \%$ of the time juice was served and $43 \%$ of the time sweets were served, they were not listed on the menus. On average, between 82 and $90 \%$ of whole fruits, vegetables, grains, proteins, and mixed dishes served were listed on the menus or substituted with acceptable items at meal or snack times.

Frequencies of foods and beverages served and listed on the menus are shown by meal and snack times in 
Table 1 Frequencies and percentages of foods and beverages served, substituted, omitted or added to meals and snacks during each meal occasion over two days of observation in New York City child-care centres, April-June 2010

\begin{tabular}{|c|c|c|c|c|c|c|c|c|c|}
\hline \multirow[b]{2}{*}{ Food and beverage groups } & \multicolumn{2}{|c|}{$\begin{array}{c}\text { Items on menu } \\
\text { and served } \\
\text { (match) } \\
\end{array}$} & \multicolumn{2}{|c|}{$\begin{array}{c}\text { Items allowed as } \\
\text { substitutions } \\
\text { (substitution) } \\
\end{array}$} & \multicolumn{2}{|c|}{$\begin{array}{c}\text { Items on menu } \\
\text { but not served } \\
\text { (omission) } \\
\end{array}$} & \multicolumn{2}{|c|}{$\begin{array}{l}\text { Items served but } \\
\text { not on menu } \\
\text { (addition) }\end{array}$} & \multirow{2}{*}{$\begin{array}{c}\begin{array}{c}\text { Total matches with } \\
2001 \text { items }\end{array} \\
\% \|\end{array}$} \\
\hline & $n$ & $\%^{*}$ & $n$ & $\% \dagger$ & $n$ & $\% \ddagger$ & $n$ & $\% \S$ & \\
\hline Milk & 385 & 93.0 & 4 & 1.0 & 22 & 5.4 & 25 & $6 \cdot 0$ & $19 \cdot 4$ \\
\hline Cheese and yoghurt & 33 & $80 \cdot 0$ & 1 & 2.5 & 10 & $22 \cdot 7$ & 7 & $17 \cdot 1$ & 1.7 \\
\hline Water & 20 & $32 \cdot 3$ & 0 & 0.0 & 49 & $71 \cdot 0$ & 42 & $67 \cdot 7$ & 1.0 \\
\hline Juice ( $\leq 100 \%$ juice) & 56 & 61.5 & 12 & $13 \cdot 2$ & 14 & $17 \cdot 1$ & 23 & $25 \cdot 3$ & $3 \cdot 4$ \\
\hline Fruits (all) & 202 & 59.6 & 111 & $32 \cdot 7$ & 40 & $11 \cdot 3$ & 26 & 7.7 & $15 \cdot 6$ \\
\hline \multicolumn{10}{|l|}{ Top five fruits } \\
\hline Orange & 29 & $67 \cdot 4$ & 12 & $27 \cdot 9$ & 4 & 8.9 & 2 & 4.7 & $2 \cdot 1$ \\
\hline Apple & 18 & $45 \cdot 0$ & 17 & 42.5 & 7 & $16 \cdot 7$ & 5 & $12 \cdot 5$ & 1.8 \\
\hline Banana & 17 & 43.6 & 17 & 43.6 & 9 & 20.9 & 5 & $12 \cdot 8$ & 1.7 \\
\hline Cantaloupe & 12 & $75 \cdot 0$ & 2 & 12.5 & 0 & 0.0 & 2 & 12.5 & 0.7 \\
\hline Pear & 10 & 76.9 & 2 & $15 \cdot 4$ & 3 & $20 \cdot 0$ & 1 & 7.7 & 0.6 \\
\hline Vegetables (all) & 239 & 74.2 & 51 & $15 \cdot 8$ & 39 & 11.9 & 32 & $10 \cdot 0$ & 14.5 \\
\hline \multicolumn{10}{|l|}{ Top five vegetables } \\
\hline Lettuce & 34 & 69.4 & 8 & $16 \cdot 3$ & 0 & 0.0 & 7 & $14 \cdot 3$ & $2 \cdot 1$ \\
\hline String beans & 16 & 84.2 & 2 & 10.5 & 0 & 0.0 & 1 & $5 \cdot 3$ & 0.9 \\
\hline $\begin{array}{l}\text { Potato } \\
\end{array}$ & 12 & $100 \cdot 0$ & 0 & 0.0 & 0 & 0.0 & 0 & 0.0 & 0.6 \\
\hline Tomato & 10 & $83 \cdot 3$ & 1 & $8 \cdot 3$ & 1 & $8 \cdot 3$ & 1 & $8 \cdot 3$ & 0.6 \\
\hline Carrots & 10 & $83 \cdot 3$ & 2 & $16 \cdot 7$ & 5 & $29 \cdot 4$ & 0 & 0.0 & 0.6 \\
\hline Grains (all) & 322 & $72 \cdot 7$ & 70 & $15 \cdot 8$ & 28 & $6 \cdot 7$ & 51 & 11.5 & $19 \cdot 6$ \\
\hline \multicolumn{10}{|l|}{ Top five grains } \\
\hline Wheat bread & 58 & $90 \cdot 6$ & 2 & $3 \cdot 1$ & 1 & 1.6 & 4 & $6 \cdot 3$ & $3 \cdot 0$ \\
\hline Graham crackers & 10 & $50 \cdot 0$ & 3 & $15 \cdot 0$ & 1 & $7 \cdot 1$ & 7 & $35 \cdot 0$ & 0.7 \\
\hline White rice & 14 & 87.5 & 0 & 0.0 & 0 & 0.0 & 2 & $12 \cdot 5$ & 0.7 \\
\hline Corn flakes & 13 & 61.9 & 6 & $28 \cdot 6$ & 0 & 0.0 & 2 & 9.5 & 1.0 \\
\hline Crackers, snack & 11 & 73.3 & 1 & 6.7 & 0 & 0.0 & 3 & $20 \cdot 0$ & 0.6 \\
\hline Proteins (all) & 102 & $87 \cdot 2$ & 4 & $3 \cdot 4$ & 13 & $10 \cdot 9$ & 11 & 9.4 & $5 \cdot 3$ \\
\hline \multicolumn{10}{|l|}{ Top five proteins } \\
\hline Chicken & 32 & $84 \cdot 2$ & 4 & $10 \cdot 5$ & 2 & $5 \cdot 3$ & 2 & $5 \cdot 3$ & 1.8 \\
\hline Egg & 20 & $83 \cdot 3$ & 0 & 0.0 & 1 & $4 \cdot 8$ & 4 & $16 \cdot 7$ & 1.0 \\
\hline Fish & 10 & $90 \cdot 9$ & 0 & 0.0 & 1 & $9 \cdot 1$ & 1 & $9 \cdot 1$ & 0.5 \\
\hline Turkey & 9 & $100 \cdot 0$ & 0 & 0.0 & 3 & $25 \cdot 0$ & 0 & 0.0 & 0.5 \\
\hline Beans & 8 & $100 \cdot 0$ & 0 & 0.0 & 4 & 33.3 & 0 & 0.0 & 0.4 \\
\hline Mixed dishes & 96 & $80 \cdot 0$ & 12 & $10 \cdot 0$ & 10 & 8.5 & 12 & $10 \cdot 0$ & 5.4 \\
\hline \multicolumn{10}{|l|}{ Top five mixed dishes } \\
\hline Spaghetti with tomato sauce & 14 & $66 \cdot 7$ & 3 & $14 \cdot 3$ & 2 & $10 \cdot 5$ & 4 & $19 \cdot 1$ & 0.85 \\
\hline Various proteins with mixed vegetables & 12 & $92 \cdot 3$ & 1 & $7 \cdot 7$ & 0 & 0.0 & 0 & 0.0 & 0.65 \\
\hline Tuna salad & 9 & 60.0 & 4 & $26 \cdot 7$ & 2 & $13 \cdot 3$ & 2 & $13 \cdot 3$ & 0.65 \\
\hline Pizza & 9 & $90 \cdot 0$ & 0 & 0.0 & 1 & $10 \cdot 0$ & 1 & $10 \cdot 0$ & 0.45 \\
\hline Rice and beans & 9 & $90 \cdot 0$ & 1 & $10 \cdot 0$ & 0 & 0.0 & 0 & 0.0 & 0.50 \\
\hline Macaroni and cheese & 8 & 88.9 & 0 & 0.0 & 1 & $11 \cdot 1$ & 1 & $11 \cdot 1$ & 0.40 \\
\hline Sweets & 21 & 39.6 & 9 & $17 \cdot 0$ & 13 & $30 \cdot 2$ & 23 & 43.4 & 1.50 \\
\hline Total foods and beverages & 1476 & 73.7 & 274 & $13 \cdot 7$ & 238 & $12 \cdot 0$ & 252 & $12 \cdot 69$ & $87 \cdot 41$ \\
\hline
\end{tabular}

${ }^{*}$ Match \% = (number of foods and beverages served that matched the foods and beverages listed on the menus/number of times those foods and beverages were served) $\times 100$.

†Substitution $\%=$ (number of acceptable substitutions served for foods and beverages listed on the menus/number of times those foods and beverages were served) $\times 100$

†Omission $\%=$ (number of foods and beverages listed on the menus that were not served/number of times those foods and beverages were listed on the menus) $\times 100$.

$\S$ Addition $\%=$ (number of foods and beverages served but not listed on the menus/number of times those foods and beverages were served) $\times 100$.

$\|$ Total match $\%=[$ (number of matched food and beverage items + number of acceptable substitutions)/total number of all foods and beverages served $] \times 100$.

Table 2. For all three eating occasions, skimmed or $1 \%$ fat milk was typically served and listed on the menu. However, type of milk was not always specified on the menu. Water was listed as a menu item on less than $10 \%$ of meal occasions and was provided to children with even less frequency. Fruit juice was served at breakfast and at afternoon snack but not at lunch. Fruits were served often at breakfast and lunch, but vegetables and protein foods were served almost only at lunch. Grains were served at all eating occasions. Substitutions for fruits and grains at breakfast and fruits and vegetables at lunch were somewhat common. Sweets were seldom offered or listed on the menus. Discrepancies between the foods and beverages served and the menu items were most common at breakfast when $18 \%$ of fruits listed on the menu were not served and during afternoon snack when $56 \%$ of vegetables listed on the menu were not served. 
Table 2 Frequencies of foods and beverages served, substituted, omitted or added during each meal occasion over two days of observation in New York City child-care centres, April-June 2010

\begin{tabular}{|c|c|c|c|c|}
\hline \multirow{2}{*}{$\begin{array}{l}\text { Food and beverage } \\
\text { groups for three } \\
\text { eating occasions }\end{array}$} & $\begin{array}{l}\text { Items on menu and } \\
\text { served (match) }\end{array}$ & $\begin{array}{c}\text { Items allowed as } \\
\text { substitutions (substitution) }\end{array}$ & $\begin{array}{l}\text { Items on menu but not } \\
\text { served (omission) }\end{array}$ & $\begin{array}{l}\text { Items served but not on } \\
\text { menu (addition) }\end{array}$ \\
\hline & $n^{\star}$ & $n \dagger$ & $n \ddagger$ & $n \S$ \\
\hline \multicolumn{5}{|l|}{ Breakfast/morning snack } \\
\hline \multicolumn{5}{|l|}{ Milk } \\
\hline Whole/2\% & 10 & 0 & 0 & 2 \\
\hline $1 \% /$ skimmed & 137 & 0 & 5 & $\overline{4}$ \\
\hline Unspecified & 0 & 0 & 3 & 0 \\
\hline Chocolate/flavouredll & 0 & 0 & 0 & 0 \\
\hline Yoghurt and cheese & 6 & 0 & 2 & 2 \\
\hline Water & 2 & 0 & 10 & 6 \\
\hline \multicolumn{5}{|l|}{ Juice } \\
\hline $100 \%$ & 25 & 5 & 4 & 9 \\
\hline Juice drink & 3 & 0 & 1 & 2 \\
\hline Fruits & 74 & 39 & 20 & 1 \\
\hline Vegetables & 2 & 0 & 1 & 0 \\
\hline Grains & 119 & 45 & 11 & 11 \\
\hline Proteins & 14 & 0 & 2 & 2 \\
\hline Mixed dishes & 0 & 0 & 1 & 1 \\
\hline Sweets & 1 & 1 & 0 & 5 \\
\hline Total & 393 & 90 & 60 & 45 \\
\hline \multicolumn{5}{|l|}{ Lunch } \\
\hline \multicolumn{5}{|l|}{ Milk } \\
\hline Whole/2\% & 7 & 0 & 0 & 2 \\
\hline $1 \% /$ skimmed & 152 & 0 & 3 & 4 \\
\hline Unspecified & 0 & 0 & 1 & 0 \\
\hline Chocolate/flavouredll & 1 & 2 & 0 & 2 \\
\hline Yoghurt and cheese & 11 & 0 & 0 & 2 \\
\hline Water & 3 & 0 & 15 & 19 \\
\hline \multicolumn{5}{|l|}{ Juice } \\
\hline $100 \%$ & 0 & 0 & 0 & 2 \\
\hline Juice drink & 0 & 0 & 0 & 1 \\
\hline Fruits & 90 & 57 & 4 & 11 \\
\hline Vegetables & 216 & 49 & 25 & 28 \\
\hline Grains & 125 & 12 & 6 & 18 \\
\hline Proteins & 74 & 4 & 8 & 8 \\
\hline Mixed dishes & 86 & 12 & 8 & 11 \\
\hline Sweets & 1 & 1 & 2 & 1 \\
\hline Total & 766 & 137 & 72 & 109 \\
\hline \multicolumn{5}{|l|}{ Afternoon snack } \\
\hline \multicolumn{5}{|l|}{ Milk } \\
\hline Whole/2\% & 1 & 0 & 0 & 0 \\
\hline $1 \% /$ skimmed & 76 & 1 & 8 & 11 \\
\hline Unspecified & 1 & 0 & 2 & 0 \\
\hline Chocolate/flavouredll & 0 & 1 & 0 & 0 \\
\hline Yoghurt and cheese & 15 & 1 & 8 & 3 \\
\hline Water & 15 & 0 & 24 & 17 \\
\hline \multicolumn{5}{|l|}{ Juice } \\
\hline $100 \%$ & 28 & 7 & 9 & 4 \\
\hline Juice drink & 0 & 0 & 0 & 5 \\
\hline Fruits & 38 & 15 & 16 & 14 \\
\hline Vegetables & 21 & 2 & 13 & 4 \\
\hline Grains & 78 & 13 & 11 & 22 \\
\hline Proteins & 14 & 0 & 3 & 1 \\
\hline Mixed dishes & 10 & 0 & 1 & 0 \\
\hline Sweets & 19 & 7 & 11 & 17 \\
\hline Total & 316 & 47 & 106 & 98 \\
\hline
\end{tabular}

${ }^{*}$ Match $=$ number of foods and beverages served that matched the foods and beverages listed on the menus.

tSubstitution = number of acceptable substitutions served for foods and beverages listed on the menus.

¥Omission = number of foods and beverages listed on the menus that were not served.

§Addition = number of foods and beverages served but not listed on the menus.

॥Chocolate milk includes two instances each of $2 \%, 1 \%$ and skimmed.

Results from the regression analyses showed that most centre and staff characteristics were not associated with the match percentage between foods and beverages listed on the menu or acceptable substitutions and what was actually served to the children. The only characteristic that was statistically significant was the staff person who makes food purchasing decisions for the centre. When the chef was primarily responsible for food purchasing decisions, 
Table 3 Child-care centre characteristics and corresponding predicted proportions of matches and acceptable substitutions between food and beverage items listed on menus and served to children during two days of observation in New York City child-care centres, April-June 2010

\begin{tabular}{|c|c|c|c|c|}
\hline & \multicolumn{2}{|c|}{ Sample descriptive statistics } & \multicolumn{2}{|c|}{ Predicted menu match proportion* } \\
\hline & $n$ & $\%$ & Proportion & $P$ value \\
\hline \multicolumn{5}{|l|}{ Centre characteristic } \\
\hline CACFPt (No) & 26 & $27 \cdot 4$ & 0.78 & 0.459 \\
\hline CACFP (Yes) & 69 & 73.4 & 0.81 & \\
\hline Head Startł (No) & 72 & $75 \cdot 8$ & 0.79 & 0.330 \\
\hline Head Start (Yes) & 23 & 24.2 & 0.83 & \\
\hline EWPH§ (No) & 61 & $64 \cdot 2$ & 0.82 & $0 \cdot 137$ \\
\hline EWPH (Yes) & 34 & 35.8 & 0.76 & \\
\hline DPHO॥ (No) & 42 & 44.2 & 0.80 & 0.748 \\
\hline DPHO (Yes) & 53 & $55 \cdot 8$ & 0.79 & \\
\hline Day of observation & & & & 0.721 \\
\hline Day 1 & 95 & $100 \cdot 0$ & 0.79 & \\
\hline Day 2 & 93 & 97.9 & 0.80 & \\
\hline Borough & & & & 0.363 \\
\hline Bronx & 34 & $35 \cdot 8$ & 0.83 & \\
\hline Brooklyn & 35 & $36 \cdot 8$ & 0.77 & 0.109 \\
\hline Manhattan & 20 & $21 \cdot 1$ & 0.81 & 0.559 \\
\hline Queens & 6 & $6 \cdot 3$ & 0.72 & 0.166 \\
\hline Staff making food purchasing decisions & & & & 0.048 \\
\hline Other & 38 & $40 \cdot 0$ & 0.79 & \\
\hline Director & 20 & 58.9 & 0.77 & 0.703 \\
\hline Chef & 14 & 48.4 & 0.87 & 0.069 \\
\hline Director and chef & 23 & 21.1 & 0.78 & 0.773 \\
\hline Staff responsible for menu planning & & & & 0.754 \\
\hline Other** & 44 & $47 \cdot 4$ & 0.80 & \\
\hline Director & 9 & 9.5 & 0.75 & 0.434 \\
\hline Chef & 19 & 20.0 & 0.78 & 0.711 \\
\hline Director and chef & 22 & $23 \cdot 2$ & 0.82 & 0.763 \\
\hline Where is food purchased & & & & 0.941 \\
\hline Othert† & 19 & $20 \cdot 0$ & 0.80 & \\
\hline Food distribution company & 64 & $67 \cdot 4$ & 0.80 & 0.897 \\
\hline Caterer & 12 & $12 \cdot 6$ & 0.78 & 0.775 \\
\hline Menu periodicity & & & & 0.349 \\
\hline Daily & 9 & 9.5 & 0.83 & \\
\hline Weekly & 76 & 80.0 & 0.80 & 0.605 \\
\hline Monthly & 8 & 8.0 & 0.70 & $0 \cdot 151$ \\
\hline Menu template used (No) & 37 & 38.9 & 0.79 & \\
\hline Menu template used (Yes) & 58 & $61 \cdot 1$ & 0.80 & 0.860 \\
\hline
\end{tabular}

${ }^{\star} P$ values are for joint tests of contrasts, either joint tests of constituent contrasts or test of contrast with the base value of each variable.

†CACFP (Child and Adult Care Feeding Program) is a programme of the US Department of Agriculture that administers federal grants to state health departments in order to provide nutritious meals and snacks to low-income individuals.

†Head Start is a comprehensive developmental programme for preschool-aged children and their families who earn household income below the federal income poverty threshold, administered by the Administration for Children and Families within the US Department of Health and Human Services.

§EWPH (Eat Well Play Hard) is a childhood obesity initiative of the New York State Department of Health. EWPH intervention involves a 6-week training programme provided free of charge by the New York City Department of Health and Mental Hygiene to child-care centres where at least $50 \%$ of the enrolled students are eligible for free or reduced-price meals.

IIDPHO (District Public Health Offices) is a programme of the New York City Department of Health and Mental Hygiene which targets resources to high-need neighbourhoods in the South Bronx, East and Central Harlem, and North and Central Brooklyn.

$\uparrow$ Other category includes dietitian, vendor and board of education.

** Interaction results between variables 'Staff making food purchasing decisions' and 'Staff responsible for menu planning' not shown, but were included because of the correlation between these variables. Other category includes dietitian, nutritionist, food-service staff, parent advisory committee caterer, board of education, central administrative office.

††Other category includes warehouse club, local grocery store and other.

there was an $8-10 \%$ higher match percentage compared with when other staff were responsible for making those decisions (Table 3).

\section{Discussion}

The menus from low-income NYC child-care centres were fairly accurate regarding the foods and beverages served to young children. Overall, $87 \%$ of the foods and beverages listed on the menus or allowed as substitutions were served. For most food and beverage groups, there were similar frequencies for when a food or beverage item was served but not on the menu ('addition') or on the menu but not served ('omission'). Fruits were more omitted than added, whereas grains were more added than omitted. These findings are not surprising because national nutrition surveillance data show that fruits are the most commonly omitted food group and grains are readily available in the current US food supply ${ }^{(13)}$. 
Our results are similar to the results from Benjamin Neelon et al.'s study ${ }^{(3)}$. In both studies, the total match percentage was $19 \%$ for milk and $20 \%$ for grains in relation to all foods and beverages served. Our study showed a higher total match percentage for fruits and vegetables compared with Benjamin Neelon et al.'s study (30\% v. 20\%), but our study showed a lower total match percentage for protein foods and mixed dishes compared with Benjamin Neelon et al. (11\% v. 16\%). Food items classified as sweets were less likely to be listed on the menu. Benjamin Neelon et al. had a match percentage of $5.5 \%$ for sweets but our study showed a total match percentage of only $1.5 \%$ for sweets.

Water was the item that was most frequently served but not listed on the menu $(67 \cdot 7 \%)$. Water was listed as a menu item on less than $10 \%$ of meal occasions and was provided to children with even less frequency. The low prevalence of water listed on menus and served at meals may be because of efforts by CACFP to ensure that children drink milk at lunch by recommending that water not be placed on the table during mealtimes ( $S$ Rhoades, CACFP Homes Administration Unit, New York State Department of Health, personal communication, July 2012). Substitutions were common for fruits and grains during breakfast and snacks, as well as for fruits and vegetables during lunch. Items in other food and beverage groups, such as milk, water, juice and mixed dishes, were substituted less frequently. These patterns of substitution may be due to the time lapse between when a menu was created and the availability of perishable food items (fruits and vegetables, dairy products) when foods or beverages were purchased or at the time of meal preparation or consumption. Although the nutritional quality of substituted foods and beverages compared with the original menu items was not evaluated, some substituted items may be less healthful than the menu items and some meals may not include foods and beverages from all major food groups.

Centres with on-staff chefs who were responsible for food purchasing had higher predicted match percentages than other centres, but which staff members were responsible for menu planning and where food was purchased for meals and snacks at child-care centres were not associated. Because the majority of centres purchased foods and beverages from food distribution companies, it is possible that our study sample was too small to have sufficient statistical power for finding an effect of food source.

\section{Study limitations}

The findings from the present study may not be generalizable to all child-care centres. First, the participating childcare centres were randomly selected from low-income neighbourhoods in NYC. Second, although centres were selected randomly from the sampling frame used in the
NYC Child Care Evaluation study ${ }^{(5)}$, about half of the eligible sampled centres participated in the classroom observation portion of this evaluation. Consequently, it is possible the centres included in the analysis did not represent the larger study sample universe. Third, menus were not collected from about $10 \%$ of the study sample. Also, some centres provided copies of invoices from catering and food-service companies in place of menus. One possible consequence of these limitations is that our findings overestimate the menu match rate of child-care centres in low-income neighbourhoods

Although not a limitation, it is important to clarify that when the foods were analysed individually, the match was $87 \%$ between foods and beverages served and the foods and beverages listed on the child-care centre menus, including acceptable substitutions. In contrast, when food and beverage matches were aggregated by meal and day the match was $79 \%$. This difference is because individual food items were weighted differently in individual-level $v$. meal- and snack-level analysis.

\section{Conclusions}

Results from the present study suggest that the menus prepared at licensed group child-care centres in low-income communities in NYC represent most of the foods and beverages served at meal and snack times at those centres. Results from our study suggest several possible areas for improvement in child-care menu and provided nutrition. First, the provision of water was rarely accurately represented on the menu. Water is both critical for human survival and an important, non-caloric substitute for many popular, but less healthy beverage options like sugar-sweetened beverages. We encourage child-care professionals, field experts and practitioners to work with child-care centres to improve the accuracy of the listing of water on menus. Second, like water, fruit juices were often misrepresented on menus. Specifically, we commonly observed that when juice was served it was not listed on the menu. Juice, even when there is no sugar added, is still a caloric beverage. Third, desserts and other sweets were often not listed on the menu when they were served. Fourth, condiments were never included on the menu. However, some condiments, such as mayonnaise, contribute non-trivial energy to meals and should be included on menus. For all the reasons that we have identified that menus accurately represent what is served, it is especially important for parents, centre employees and health promotion specialists that lownutrient, high-energy items like juice and desserts are shown on the menus. When informed about the service of these types of foods and beverages, public health professionals and practitioners can intervene with nutrition education and menu planning assistance and parents be better informed about what their child is being served and most likely consuming throughout the day. 
Further research is encouraged to determine whether the centre directors and staff need assistance with making the menus more accurate and consistent, and where challenges may be in terms of meeting licensing and CACFP reimbursement requirements. It is also important to evaluate how planned menus can be used as nutrition education for parents and caregivers when feeding young children outside the child-care environment.

\section{Acknowledgements}

Acknowledgements: Technical assistance was provided by the Centers for Disease Control and Prevention (CDC) National Center for Chronic Disease Prevention and Health Promotion Division of Nutrition, Physical Activity and Obesity. ICF International served as the lead contractor for the study in conjunction with the NYC DOHMH. The authors thank the centre directors, teachers and staff for their help with data collection. They also thank two students (Minh Tieu, Simone Walters) who helped enter dietary data into the ASA24 system. The findings and conclusions in this report are those of the authors do not necessarily represent the official position of the CDC or any of the other project agencies. Financial support: This project was funded by a grant (number 65425) from the Robert Wood Johnson Foundation to the National Foundation for the CDC. The funders had no role in the design, analysis or writing of this article. Conflict of interest: None. Authorship: A.B. contributed to data collection, conducted the analysis, and took primary responsibility for drafting this manuscript. L.B.D. assisted in designing the study, provided guidance on the analysis, and provided substantial contributions to the substance and editing of the paper. L.K.K. conceptualized and oversaw this study, provided guidance on the analysis, and provided substantial contributions to the substance and editing of the paper. Ethics of buman subject participation: This study was conducted according to the guidelines laid down in the Declaration of Helsinki and all procedures involving human subjects/patients were approved by the institutional review boards of the NYC DOHMH and ICF International.

\section{References}

1. American Dietetic Association (2005) Position of the American Dietetic Association: Benchmarks for Nutrition Programs in Child Care Settings. J Am Diet Assoc 105, 979-986.

2. New York State (2005) State Regulations for Child Care Centers Part 418, Section 1.12. http://ocfs.ny.gov/main/childcare/regs/ 418-1\%20DCC\%20effective\%206.1.15.pdf (accessed March 2016).

3. Benjamin Neelon SE, Copeland KA, Ball SC et al. (2010) Comparison of menus to actual foods and beverages served in North Carolina child-care centers. J Am Diet Assoc 110, 1890-1895.

4. Fleischhacker S, Cason KL \& Achterberg C (2006) 'You had peas today?': a pilot study comparing a head start child-care center's menu with the actual food served. J Am Diet Assoc 106, 277-280.

5. Breck A, Goodman K, Dunn L et al. (2014) Evaluation design of New York City's regulations on nutrition, physical activity, and screen time in early child care centers. Prev Chronic Dis 11, E184.

6. Dixon LB, Breck A \& Kettel Khan L (2016) Comparison of children's food and beverage intakes with national recommendations in New York City child-care centres. Public Health Nutr (Epublication ahead of print version).

7. Benjamin SE, Neelon B, Ball SC et al. (2007) Reliability and validity of a nutrition and physical activity environmental self-assessment for child care. Int J Behav Nutr Phys Act 4, 29.

8. Ward D, Hales D, Haverly K et al. (2008) An instrument to assess the obesogenic environment of child care centers. Am J Health Behav 32, 380-386.

9. Crepinsek MK, Burstein NR, Lee EB et al. (2002) Meals Offered by Tier 2 CACFP Family Child Care Providers Effects of Lower Meal Reimbursements A Report to Congress on the Family Changes Study. Appendix B: Menu Survey and meal observation record. http://www.ers.usda. gov/media/1788254/efan02006.pdf (accessed July 2012).

10. National Cancer Institute (2009) Automated SelfAdministered 24-Hour Recall (Beta version; FNDDS 1.0) (ASA24). Bethesda, MD: NCI.

11. New York City Department of Health and Mental Hygiene (2006) Notice of Adoption of Amendments to Article 47 of the New York City Health Code. http://frac.org/newsite/wpcontent/uploads/2009/06/nyc_cacfp_childcare_nutrphysact_ law.pdf (accessed July 2012).

12. New York State Department of Health (2011) Child and Adult Care Food Program: Healthy Child Meal Pattern. http://www.health.ny.gov/prevention/nutrition/cacfp/docs/ cacfp-102.pdf (accessed July 2012).

13. Krebs-Smith SM, Guenther PM, Subar AF et al. (2010) Americans do not meet federal dietary recommendations. J Nutr 140, 1832-1838. 